\title{
A Qualitative Exploration of Prisoners' Strategies for Coping with Food Insecurity in Prisons in Kinshasa, DRC
}

Danny Mvula Muanga Badila ( $\sim$ badiladanny@gmail.com )

Université de Kinshasa https://orcid.org/0000-0003-1135-996X

Sphindile Nonhle Mapumulo

University of Kwazulu-Natal

Christiane Horwood

University of Kwazulu-Natal

Vaughn Mitchell John

School of Education University of Kwazulu-Natal

Mala Ali Mapatano

University of Kinshasa

Research article

Keywords: Prisoners, nutrition, food insecurity, human rights, health, DRC

Posted Date: November 22nd, 2021

DOI: https://doi.org/10.21203/rs.3.rs-1066666/v1

License: (9) This work is licensed under a Creative Commons Attribution 4.0 International License.

Read Full License 


\section{Abstract}

Background: Contravention of prisoners' basic human rights, over-crowding, poor living conditions, food insecurity, disease and lack of access to medical care in prisons constitute a serious public health concern in many low-income countries in Africa, including the Democratic Republic of Congo (DRC). This study aimed to explore prisoners' experiences of food insecurity and strategies prisoners employ to overcome food insecurity in two prisons in Kinshasa, DRC.

Methods: A qualitative study was conducted among 31 prisoners, both men and women. In-depth interviews were conducted in N'dolo and Makala prisons by two researchers in the local language (Lingala). For security reasons of prisoners interviews were not audio recorded, however, interviewers took thorough notes during interviews. Thematic analysis was used to analyze data

Results: Prisoners in both prisons described experiences of food insecurity. Food was normally served once a day, late in the afternoon. Prisoners complained about a monotonous diet, and that the food was of poor quality, inadequate quantity, and was unhygienically prepared. Most prisoners relied on outside support from family and friends for food provision, but those who did not have such support endured hunger and severe food insecurity. Prisoners employed different coping strategies to manage their hunger, which strategies they described for less severe, severe and very severe food insecurity depending on what they had to do to survive. Strategies included prisoners sharing food with each other, drinking water throughout the day, selling their belongings to buy food, begging food from visitors, looking for food in rubbish bins, or exchanging sex for food.

Conclusion: Urgent attention is needed to improve nutrition and living conditions in Congolese prisons. All stakeholders need to formulate a comprehensive plan that will address issues faced by prisoners and improve their quality of life. Regular inspection of prisons is essential to ensure prisoners are treated fairly and their human rights are respected.

\section{Introduction}

In many low-income countries, health, health care and quality of life in prison is a public health concern [1]. Prisoners often live in an environment that is unhygienic and overcrowded, without proper ventilation or sanitation. In many settings inadequate access to food, water and medical care has been reported, and prisoners may be poorly clothed [2]. As a result of poor living conditions and inadequate medical care, infectious diseases such as tuberculosis and HIV/AIDS are easily spread and are poorly treated [3-5]. African governments have frequently failed to provide adequate funding for prison services, leading to poor maintenance of prisons, inadequate infrastructure, corruption, understaffing, and lack of basic supplies, including food. Some prisons in Sub-Saharan African (SSA) countries have no health facilities, and even if available, these are poorly resourced with staff shortages, lack of medical equipment, and limited essential medicines $[5,6]$. The resulting poor health and poor nutritional status of many prisoners in SSA is a serious breach of their basic human rights [7]. 
The International Covenant on Economic, Social and Cultural Rights (Article 12(1) of 1966) establishes "the right of everyone to the enjoyment of the highest attainable standard of physical and mental health" [8] and article 25 establishes the responsibility of the state to ensure an adequate standard of living for everyone, including adequate food. This statement includes prisoners, who have the right to enjoy good health, and being in prison does not mean that their human rights should not be respected [9]. The Democratic Republic of Congo (DRC) constitution guarantees "the right to health and food security" for all, which includes prison inmates [10]. The country also makes the commitment that every prisoner shall be provided with food of adequate nutritional value, in line with the United Nations Standard Minimum Rules for the Treatment of Prisoners, known as the Nelson Mandela rules, which the DRC has endorsed $[11,12]$. These rules aim to support prison reform and promote respect for prisoner's inherent dignity as human beings. In particular, Mandela rule 22 states that "Every prisoner shall be provided by the prison administration at the usual hours with food of nutritional value adequate for health and strength, of wholesome quality and well prepared and served. Drinking water shall be available to every prisoner whenever he or she needs it" [11].

However, the DRC is failing to protect human rights of prisoners, thus violating prisoners' human rights. Prisons in DRC are among the most overcrowded in the world [13], and the state has stopped providing food to prisoners in many facilities [14]. Mortality among prisoners in the DRC is high, with major causes of death being malnutrition and tuberculosis [15]. In addition, Avocats Sans Frontiers reported that prisoners are poorly supported by the public services [16]. The prisons are largely dependent on support from the private sector or non-governmental organisations which include faith charities, national and international non-governmental organisations, and representation from international institutions [17]. Little is known about how prisoners cope with lack of food and the strategies they employ to try to maintain their food intake. This study aimed to explore prisoners' perceptions and experiences of food insecurity in prison for the purpose of advocacy and to inform interventions to improve nutrition in Congolese prisons.

\section{Methods}

A qualitative study was undertaken among prison inmates using in-depth interviews.

\section{Study setting}

The study was conducted in the two-prison facilities of Makala and N'dolo, which are respectively located in the districts of Selembao and Barumbu in Kinshasa, DRC. Makala is the biggest prison in DRC. Both prisons are commonly described as overcrowded. Makala and N'dolo prisons have a carrying capacity of 1500 and 550 prisoners respectively. During the study period, Makala central prison and N'dolo Military prison hosted 5500 prisoners and 1545 prisoners respectively, more than three times their capacity, including both men and women. Prison directors and general staff are reported to profit from the prisons conditions by selling sleeping arrangements to prisoners who can afford to pay and requiring payment for family visits [18]. 
Both prisons have a visiting area, administrative buildings (social welfare, security offices etc.), kitchen, a chapel for worship, a soccer field and a medical centre. The administrative team comprises a Guardian for Makala prison and a Commander for N'dolo and their deputies, secretariat, clerk, medical staff, supervisors and guard house.

Each prisoner is given a daily ration called vungule, approximately 500 grams per day, which is a meal made of mixed beans and corn. The diet is monotonous with the same food being provided once daily in the afternoon. Every week women prisoners are given raw food by the prison to cook for themselves. Men do not get such services, as they wait for the prison ration to be served or wait for relatives and family members to bring food for them. Family members may only bring cooked food which is first thoroughly checked by the security before being given to the prisoner.

\section{Recruitment and sampling}

Prisoners were recruited to participate in the study based on their willingness to be interviewed. Convenience sampling was used to identify and recruit participants. The researchers approached each prisoner, explained the purpose of the study and agreement for participation was obtained if the prisoner was willing to participate in the study.

\section{Data collection}

In-depth interviews (IDIs) were conducted using an interview guide that was administered to prisoners in Lingala, one of the four national languages in DRC. The questionnaire included the socio-demographics of participants and their experiences of coping with the food insecurity situation. Data were collected by two researchers. One researcher focused on collecting data from female prisoners and the other researcher collected data from both from male and female prisoners. Due to security concerns after a recent prison escape, interviews were not audio recorded but the researcher took thorough notes during the interview. Researchers would ask a question, and take notes in Lingala while the participants were speaking. Field notes were translated into French by the researcher.

\section{Data analysis}

A thematic analysis was used to analyse the data. The data was coded manually using highlighters and coloured pens to identify themes. Codes referred to the most basic segment of the raw data that was organised into meaningful groups (1).

\section{Ethical considerations}

The study proposal was reviewed and approved by the School Public Health of Kinshasa Ethics Committee referenced as approval number N0 ESP/CE/033 2017. Permission was obtained from the Makala central and N'dolo military prisons' authorities respectively referenced as NOJUST.04/DSP/MMM/PB 297/233/2017 and N0480/MDNAC-R/SG DEF/DAPM/ART/DAL/17. During recruitment of participants, prisoners were approached individually by researchers who introduced themselves and read the participant information sheet to the prisoner. The purpose and voluntary nature 
of the study was clearly explained and prisoners were informed that they were free to withdraw at any stage of the study. Verbal informed consent was obtained from the inmates in the presence of a witness.

\section{Results}

A total of 31 in-depth interviews were conducted in November 2017, with twenty-four interviews in Makala and seven in N'dolo. Nineteen participants were male and 12 were female. The age range of participants was from 29 to 48 years. Sociodemographic characteristics of participants are shown in Table 1. Most of the participants had been working before being incarcerated, for example as a hairstylist, running a small business, car driver, policy officer, working in private sector, military, etc. Most of the prisoners stated they did not receive visits, from relatives or from anyone else. 
Table 1

Sociodemographic characteristics of participants

\begin{tabular}{|c|c|c|}
\hline Characteristics & $\mathbf{n}$ & $\%$ \\
\hline \multicolumn{3}{|l|}{ Gender } \\
\hline Female & 12 & 39 \\
\hline Male & 19 & 61 \\
\hline \multicolumn{3}{|l|}{ Marital status } \\
\hline Married & 14 & 45 \\
\hline Separated & 4 & 13 \\
\hline Divorced & 1 & 3 \\
\hline Widow & 4 & 13 \\
\hline Single & 8 & 26 \\
\hline \multicolumn{3}{|l|}{ Religion } \\
\hline Catholic & 12 & 39 \\
\hline Reveil church & 12 & 39 \\
\hline Islam & 4 & 13 \\
\hline Protestant & 2 & 6 \\
\hline Kimbanguist & 1 & 3 \\
\hline \multicolumn{3}{|c|}{ Number of years of schooling } \\
\hline None & 2 & 6 \\
\hline$<6$ & 3 & 10 \\
\hline 6 & 0 & 0 \\
\hline$<12$ & 16 & 52 \\
\hline 12 & 5 & 16 \\
\hline$<17$ & 0 & 0 \\
\hline 17 & 5 & 16 \\
\hline \multicolumn{3}{|c|}{ Estimated number of visits per week } \\
\hline None & 19 & 62 \\
\hline 1 time & 6 & 19 \\
\hline More than 1 & 6 & 19 \\
\hline
\end{tabular}


The following section presents main themes of the study:

\section{Prisoners receive inadequate, poor quality food}

Prisoners in both prisons, Makala and N'dolo, were poorly fed, due to shortage of food in both prisons. Prisoners mentioned that they would spend the whole day without eating any food and were hungry most of the time.

I endure hunger until the food is distributed around 5-6 p.m. We are served a cup of corn and beans and although you're still hungry, you have to put up with it. That's why you see other people here going psycho (liboma, Lingala word meaning psychological trouble) it's through neglect [Participant 31, male, 30 years]

I bip (sending text message) when hunger is severe and sleep hungry when I have no choice (Participant 29 , female, 40 years)

Although food is served in prisons, it is usually served later in the day and prisoners reported that the food was of poor quantity and quality, and prisoners complained that they were not satisfied with the food. Most prisoners complain about lack of food diversity, stating that most of the time they are served with the same meal everyday called 'vungule' which is a mixture of corn and beans. "I wish we had diversified food instead of giving us the beans every day. [P4FM]". Living in hunger was either because some prisoners did not want to eat prison food or because there was no food to eat.

I must endure the hunger, be content with this situation. Eat small amounts found or obtained [Participant 3 , female, 34 years]

The unhygienic environment and poor quality of food resulted in some of the prisoners not wanting to eat food prepared in the prison kitchen. They preferred to cook their own meal or go to bed hungry if they did not have food. Some prisoners were cautious of their health and were following doctor's orders.

... It is poorly prepared food in unsanitary conditions. [Participant 18, male, 41 years]

I eat prison food, only when they prepare rice or fufu like porridge with beans, but if it's the vungule I don't eat; I prefer to sleep hungry because the way it is prepared, as it comes out of the bag with pebbles, wood debris, all in it. Besides, a doctor advised me not to eat it because it causes cough and therefore tuberculosis and there you will go to the VIIB pavilion [health facility] for tuberculosis and mental patients. [Participant 26, male, 44 years]

Female prisoners were usually given raw food, supplied by the prison every two days. However, the prisons do not provide cooking materials such as coal and wood. Raw food was only provided to female prisoners, male prisoners only get cooked food.

We are preparing little by little because after two days the prison gives us a supply of 2 measures (sakombi) of corn flour, 2 measures of cassava flour and 5 litres of oil for all the inmates. The embers we 
buy and if we have no money we ask the neighbour. [Participant 13, female, 30 years]

\section{Prisoners were dependent for food on support from outside the prison}

Most prisoners stated that they are dependent on the support from visitors such as family members, friends and other community structures such as the church for help with food provision. Prisoners who have strong support from the outside were less likely to experience hunger.

Personally, I have not yet experienced this situation because I always have what I need and if I notice that my supply tends to decrease, I call my wife who supplies me. (Participant 20, male, 47 years)

I have the opportunity to receive visitors on Wednesday and Sunday. On the days close to a visit, I don't miss anything to eat, I've had enough. [Participant 5, female, 32 years]

Prisoners who did not get any visit were more vulnerable and were often living in hunger. Prisons accommodate prisoners from different areas of the DRC, including foreigners. Therefore, prisoners from afar mostly depended only on rations from the prison since they do not get visitors to provide them with extra food, making their life in prison very difficult.

It's because I don't have anyone, I don't have a family in Kinshasa. Some prisoners have families and live easily here in prison. [Participant 7, female, 43 years]

It is the lack of visits that is at the root of this situation [Participant 1, female, 37 years]

It is the possibility of being visited that influences my withdrawal condition. Like me, my family lives in Kisantu and visits me once a month. [Participant 12, female, 29years].

\section{Prisoners' perceptions about the cause of the food insecurity}

Prisoners mentioned that lack of support from the government is the main cause of hunger within prisons. Prisoners stated that they take full responsibility for being in prison because of their crimes, however the government must take care of them so that they can be fully rehabilitated.

We are not doing anything, we have no money here. It is the government that is at the root of all these problems. We are punished, but we must not be deprived of food ... We recognize that we are bad people but we want to live in peace. When the child is punished too much, it causes him to act badly. These conditions of hunger do not help us to improve ourselves on the other hand they make us psychologically sick with all its consequences [Participant 11, female, 39 years]

The prisoners also felt that prison administration exacerbated their hunger situation by delaying serving food. Food is served once a day in the afternoon, but sometimes it is served later in the evening. 
... the distribution depends on the will of the governor who can decide the distribution immediately or delay it around 6 p.m. Sometimes food gets in here around 8-9 p.m. [Participant 27, male, 48 years]

Furthermore, kitchen staff who are responsible for preparing and serving meals to prisoners contributed to creating hunger among prisoners by withholding food from the general population to sell to prisoners who had money to buy it. This was confirmed by prisoners who actually bought food from the prison kitchen stating that they buy extra food from the kitchen to avoid hunger. Other prisoners complained that kitchen staff were giving prisoners small portions of food that was unsatisfactory, leaving many prisoners feeling hungry.

It is the people in charge of the kitchen who know the reality. They give us small amounts of food that no one even a baby can be satisfied by taking them [Participant 11, female, 39 years]

... If I have 200FC I can buy the vungule through my friends who work in the kitchen because what we are served is just a cup so if I am not satisfied I buy. [Participant 27, male, 48 years]

... The chefs take our food to sell and serve us as they wish. [Participant 28, male, 35 years]

Witnessing living conditions inside the prison environment, one of the prisoners stated that he would use his prison life experience to advocate for prisoners once he gets out of prison. His main goal is to change how prisoners are being treated and ensure that their basic needs are met.

... When I get out of prison, I will be making pleas, fundraising appeals for prisoners using my testimony. The lack of food weakens us psychologically and physically. We are easily injured even at the slightest touch [Participant 11, female, 39 years]

\section{Prisoners strategies for coping with food insecurity}

Prisoners who were living with hunger applied different coping strategies to manage their hunger and obtain food from different sources including prison food. These were described by prisoners as strategies for less severe, severe and very severe food insecurity depending on what they had to do to survive the hunger.

\section{Less severe strategies}

When prisoners still had access to food they employed less severe strategies to ensure that the food lasted longer until they get more food from prison or from friends and relatives. Less severe strategies included eating small quantities of food so that they could save some for the upcoming days until they get more food; eating less nutritious food such as drinking sugar water or tea to alleviate hunger and save food; not sharing food; and ensuring that they always have cash by conducting small business activities inside prison. One prisoner explains how he initially shared his food but had to stop to make sure he had enough food for himself. 
... in fact, at the beginning, when I did not have any experiences, if you have food, you eat without being worried and share with others. Now you ascertain that visits are not regular so you must change.

[Participant 23, male, 38 years]

Another prisoner gives an example of how he uses his own money to purchase commodities to sell in prison, which provides enough profit to ensure he is able to eat regularly.

I buy some commodities (cigarettes, sugar, biscuits, etc.) for selling. That helps me to maintain resource and to feed myself regularly. [Participant 10, female, 43 years]

\section{Severe strategies}

When prisoners experienced insufficient food they employed a number of increasingly severe strategies. These strategies included asking other prisoners for food; drinking large amounts of water before they go to sleep; providing services to fellow inmates such as doing laundry or cooking food in exchange for money or food; or borrowing from other prisoners at high interest rates.

If I miss food, I drink about 1 litre of water and then I sleep or I ask my neighbours [for food]. [Participant 18 , male, 41 years]

I do jobs (call people, clean clothes) to have some money to buy food. If I can't find anything, I stay hungry. [Participant 9, female, 33 years]

Sometimes I turn to someone who can lend me 500FC with interest and give him 1000FC until the day I have a visit. [Participant 28, male, 35 years]

If I miss [food], I would rather make my own tea and drink it instead of going to borrow or I can fast [go hungry]. [Participant 30, male, 41 years]

\section{Very severe strategies}

There were times where prisoners did not have access to any food or had run out of food. In such severe situations prisoners stated they would miss food for the whole day or drink water throughout the day. Some prisoners would resort to selling their possessions such as clothes and shoes to other prisoners so they could get money to buy food. Some prisoners had sex with other prisoners in exchange for food.

If I realize that 3-4 days I am missing something [food] I can take my pants or a good shirt to sell. With this money, I buy the rice that I can eat for 2 days by splitting it is what gives me balance. I can stay from morning until 3 p.m. with water and around 8 p.m. I eat my rice and then go to sleep straight away. [Participant 26, male, 44 years]

I am on the safety committee in my pavilion and it happens as part of our surveillance work, to catch people having sex between men to have food just because the other is not satisfied [does not have food] or is looking for money for example 1000FC. The one who has the means or the food, promises lto give it to] his teammate in exchange for sex. [Participant 31, male, 30 years] 
Some prisoners are ashamed to ask food or help from other prisoners, hence they endured hunger. Some prisoners would go through bins searching for disposed food.

...some have to look for food from the bin but he is not madman ... just because he is hungry [Participant 27, male, 48 years]

I'm only happy with what we get here at the prison. I don't do anything else. I'm ashamed to ask, to have mean answers that affect (me) more. [Participant 11, female, 39 years]

I am only satisfied with the prison ration. I'm not doing anything else, I can't ask for or provide paid services. I am ashamed. [Participant 12, female, 29 years]

\section{Prisoners' recommendations}

To address the hunger within the prisons, prisoners recommended that food must be served at least twice a day, in the morning and in the evening, and the quantity of food should be increased. Prisoners also wanted to be served with a variety of foods that are properly and hygienically prepared.

let us improve the situation such that in the morning we take the porridge and in the afternoon the meal. [Participant 28, male, 35 years]

That we change the way we eat, diversify the food, serve ourselves breakfast so that the sugar gives us a little strength. [Participant 5, female, 32 years]

\section{Discussion}

This study describes appalling conditions of hunger and food insecurity in two prisons in Kinshasa, DRC, and illustrates some of the strategies employed by prisoners to cope with food insecurity. Shortage of food in prisons is a serious public health and human rights concern that needs to be addressed to improve quality of life among prisoners. The situation described by participants is in violation of the prisoners' human rights and the actions prisoners are forced to take to alleviate hunger are dehumanising and violate prisoners' right to human dignity. This is in direct contravention of the Mandela rule 22 which states that every prisoner must be provided with nutritious food at usual hours $[11,12]$.

Prisoners in this study, reported receiving one meal late in the day, which was of a small quantity and of poor quality, suggesting that prison administrators do not prioritise prisoners' dietary intake, health and wellbeing. Prisoners in both prisons suffered from food shortages due to poor distribution of food. Some prisoners talked about going to bed hungry because they missed prison food. Although it was not clear how they missed food, but it is possible that prison runs out of ration before everyone receives food. Overcrowding may be the reason for this since rations are budgeted according to prison carrying capacity but not the actual population. Directors of other prisons in DRC stated that rations were insufficient due to overcrowding, hence they serve one meal per day [10]. Distribution of food according to gender is another problem that needs to be addressed. The basic principle for the treatment of prisoners states that "There 
shall be no discrimination on the grounds of race, colour, sex, language, religion, political or other opinion, national or social origin, property, birth or other status" [19]. Women were given raw food to cook while men received cooked meal from the prison for example in case of N'dolo prison. Although women were not happy about food they received, they were in a better situation than men who received the same poorly prepared meal every day.

Adequate dietary intake is essential for good health and wellbeing. Similarly, meal frequency and timing are significant aspects of nutrition [20]. Lack of nutritious food supply leads to poor health, both physically and mentally, and eventually death. According to the United Nations report [18] 223 prisoners died in detention in DRC prisons in year 2018 and malnutrition was one of the causes of death [21]. In January 2020 the BBC news reported that 17 prisoners in Makala prison in DRC died due to malnutrition and this is not the first incident where prisoners died because of hunger [2]. Malnutrition greatly increases vulnerability to infectious diseases. Kalonji, De Connick [1] stated that malnutrition was one of the factors associated with increased risk of prisoners contracting TB in prisons, and poor outcomes for prisoners contracting TB [1]. Studies in many countries have associated food insecurity and prevalence of HIV infection [22-24]. Lack of food is one of the contributing factors of HIV infection in prisons. In this study prisoners reported that prisoners were practising transactional sex to get food. This is an unsafe coping strategy given the high prevalence of HIV in prisons and prisoners may have unprotected sex due to lack of condom provision [25]. It is also important to note that not only prisoners are at risk of contracting communicable disease such as TB but also the prison staff and visitors can be affected, and transmit diseases to their family members and community at large. Therefore, it is imperative to improve conditions within prison environment to prevent the risk of spreading diseases within the prison and the wider community.

Government as the major stakeholder needs to take full responsibility to provide for the prisoners and ensure that there are enough funds allocated to the prison system. This will enable the prison administrators to run prisons and improve effective rehabilitation of prisoners. Prisoners acknowledged that they are in prison for crimes they have committed but the prison environment is not conducive to improving their lives, and severe hunger leads to desperate actions to get food. The environment is overcrowded, with poor sanitation, lack of nutritious food and hunger, all of which lead to poor health and wellbeing. Therefore, there is great need to reform prisons in DRC to ensure a basic standard of living. Amnesty International [10] reported that the DRC government has overlooked the responsibility to ensure the basic standard of prison conditions. Furthermore there is lack of donor support for the prison system resulting in poor maintenance of prisons [10].

Prison administrators find it difficult to provide an adequate standard of nutrition with the limited funds they receive from government. The Bureau of prisons is given $\$ 2.27$ per prisoner per day [26]. This amount is not enough to cover prisoners' basic needs, including adequate amounts of nutritious foods. However, prison administrators should consider developing and employing strategies to create funds to address prisoners' needs. When State funds are limited, there are a number of organisations and agencies that can make contribution in helping the State to provide for prisoners and that can only 
happen if they are informed by the government or prison management. There are other interventions that can be implemented by prison authorities to address hunger and food insecurity in prisons. For example, implementing agricultural practices such as planting of fruits and vegetables, poultry rearing, within the prison environment are some interventions that can create and increase food diversity. These activities can be carried out by prisoners and managed by the authorities, and they are cost effective.

Prison staff members serve as key participants in providing prisoners basic needs and to provide control and orderliness within the prison [27]. However, some staff members did not fulfil their role. There were complaints in this study that kitchen staff were robbing prisoners of their food and selling it to prisoners who can afford to buy it, resulting in other prisoners suffering hunger. Therefore, supervision and discipline measures must be put in place to ensure that prison staff abide by the rules and respect prisoners' rights. Prison administrators should put the complaint system in place so that prisoners can voice their grievances about treatment or services they receive from staff members, and also ensure that such complaints are addressed effectively. The Mandela rule 56 (3) states that each day a prisoner must be given an opportunity to make requests or complaints regarding his or her treatment to any competent authorities within prison administration [11, 12].

Internal prison inspection is an important intervention that must be practised regularly to ensure that prisons are managed in line with existing laws, regulations, policies and procedures, and that the rights of prisoners are protected $[11,12]$. Furthermore, prisoners must be included in the inspection process, this will allow prisoners to express their views and concerns regarding their stay in prison. Good governance within the prison environment is obligatory to ensure basic principles of the Nelson Mandela rules are visible and that prisoners' rehabilitation processes are effective.

Prisoners were largely dependent on family and friends for food provision. Considering the socioeconomic status of most families in DRC, depending on family members for food supply might be still an unreliable option as most families live in poverty. Furthermore, there may be other circumstances that prevents family members to provide food to their loved ones in prison such as distance, transportation or outbreak of diseases.

Prison is an environment that is meant to rehabilitate prisoners so that they can live a crime-free life after being released. However, this is hard to achieve when prisoners are living in terrible conditions, with little or no provision of basic needs. Hunger suffered by prisoners may have led them to be involved in unlawful activities within the prison environment. Their state of living inside prison was based on a survival mode which may result in long-term effects in their lives. Families and communities will have to deal with former prisoners who have been exposed to a dire environment and may be affected mentally due to the living conditions he/she has been exposed to. Studies suggest that prisoners experience depressed moods and/or stress symptoms, for example one in nine prisoners suffer some form of common mental disorder [28]. Durcan and Zwemstra [29] mentioned that the mental well-being of prisoners can worsen if their needs are not met. 
There are many other factors within the prison environment that challenge prisoners' mental well-being. Poor diet, overcrowding, lack of access to services such as health care and counselling are amongst those factors [29]. Therefore, it is imperative to ensure that the standard of living in prisons is of good quality and that prisoners' rights are respected. This can be achieved through strengthening coping mechanisms that would allow prisoners to live a healthy life inside and outside prison. Prisoners need reliable and tangible support from people and an environment that facilitates self-improvement. Prisoners need to be cared for and appreciated which is important for emotional sustenance. There is also a need for activity and distraction through physical exercise and reading [29]. These are important factors that should be provided to prisoners to ensure that their rehabilitation process is productive and prepares them to face life outside prison.

\section{Strengths and limitations of the study}

A possible limitation of the study was the convenience sampling, as a result of which some prisoners, particularly those with severe food shortage or illness, may have been unwilling to participate. Another limitation was observer's bias whereby participants may not have disclosed information that was socially unacceptable, particularly those activities like transactional sex or eating from the rubbish bins. As a strength, despite some methodological limitations, this study offers rich descriptions and detailed information on a difficult to reach community about a key public health issue.

\section{Conclusion}

Violation of human rights among prisoners in Kinshasa is prevalent. Quality of life in prison is poor and prisoners are prone to a number of diseases due to malnutrition, overcrowding and the unhygienic environment. There is an urgent need for Government together with all other relevant stakeholders to apply a comprehensive plan that will improve the living conditions of prisoners and ensure that prisons conditions are in line with international standards. There is also a need for government to build new prisons to address overcrowding. Inspections of prisoners must be strengthened to ensure that prison administration respect rights of prisoners and that prisoners are treated with respect and dignity.

\section{Abbreviations}

DRC- Democratic Republic of Congo

IDIs- In-depth interviews

HIV/AIDS- Human Immunodeficiency virus/Acquired immunodeficiency syndrome

SSA- Sub-Saharan African

TB- Tuberculosis 


\section{Declarations}

\section{Ethical approval and consent to participate}

Ethical clearance was obtained from the Ethics Committees of Kinshasa School of Public Health referenced as approval number NO ESP/CE/033 2017. Consent was obtained from each individual respondent during data collection. Privacy and confidentiality were maintained throughout the study.

\section{Consent for publication}

Not applicable

\section{Availability of data and materials}

All data, transcripts and supporting documents for this study are available at the Kinshasa School of Public Health, University of Kinshasa. They will be made available upon request to the leading author.

\section{Competing interests}

The authors declare that they have no competing interests

\section{Authors' contribution}

BMMD initiated the study and wrote the proposal. MAM, SM, CH and VJ contributed to the design of the study. BMMD collected data and supervised fieldwork. BMMD and SM undertook data analysis with support from $\mathrm{CH}, \mathrm{MAM}$ and VJ. BMMD and SM wrote the manuscript. All authors contributed to drafting and revising of the manuscript. All authors approved the final version.

\section{Acknowledgments}

The authors would like to thank all participants in this study, particularly prisoners of Makala and N'dolo prisons, for availing themselves in sharing their experiences with us. They would also like to thank Zarine LUTONAMO the co-investigator for her availability and courage to conduct an interview in the prison. We are also grateful to the prison authorities for facilitating this research.

\section{References}

1. Kalonji, G.M., et al., Prevalence of tuberculosis and associated risk factors in the Central Prison of Mbuji-Mayi, Democratic Republic of Congo. Tropical medicine and health, 2016. 44(1): p. 1-6.

2. BBC News, DR Congo jail: Inmates starve to death in Makala Prison. 2020.

3. Reid, S.E., et al., Tuberculosis and HIV control in sub-Saharan African prisons:"thinking outside the prison cell". Journal of Infectious Diseases, 2012. 205(suppl_2): p. S265-S273.

4. O'Grady, J., et al., Tuberculosis in prisons in sub-Saharan Africa-the need for improved health services, surveillance and control. Tuberculosis, 2011. 91(2): p. 173-178. 
5. Telisinghe, L., et al., HIV and tuberculosis in prisons in sub-Saharan Africa. The Lancet, 2016. 388(10050): p. 1215-1227.

6. Van Hout, M.C. and R. Mhlanga-Gunda, Contemporary women prisoners health experiences, unique prison health care needs and health care outcomes in sub Saharan Africa: a scoping review of extant literature. BMC international health and human rights, 2018. 18(1): p. 1-12.

7. UN General Assembly, Universal declaration of human rights. UN General Assembly, 1948. 302(2): p. 14-25.

8. United Nations Human Rights, International Covenant on Economic, Social and Cultural Rights. Adopted and opened for signature, ratification and accession by General Assembly resolution $2200 \mathrm{~A}$ (XXI) of 16 December 1966 entry into force 3 January 1976, in accordance with article 27. 1966.

9. Gatherer, A., R. Jürgens, and H. Stöver, Health in prisons: a WHO guide to the essentials in prison health. 2007: WHO Regional Office Europe.

10. Amnesty International, The time for justice is now. New strategy needed in the Democratic Republic of the Congo. 2011.

11. UNODC, The United Nations Standard Minimum Rules for the Treatment of Prisoners (the Nelson Mandela Rules). 2015.

12. McCall-Smith, K., United nations standard minimum rules for the treatment of prisoners (Nelson mandela rules). International Legal Materials, 2016. 55(6): p. 1180-1205.

13. Human Rights Watch, DR Congo: Prisons Face Covid-19 Catastrophe Greater Action Needed to Reduce Numbers, Allocate Food Funds, Improve Hygiene. 2020.

14. MONUSCO, Rapport sur les conditions de détention dans les prisons et cachots de la RDC. 2005.

15. Kalonji, G.M.P., et al., Factors associated with prison survival: Study in the Democratic Republic of Congo. Sante Publique, 2019. 31(5): p. 715-722.

16. A, F.A.s., Pour quoi détenir ? Réalités de la détention des personnes en République Démocratique du Congo. 2015.

17. Mobekk, E., Security sector reform and the UN mission in the Democratic Republic of Congo: Protecting civilians in the East. International Peacekeeping, 2009. 16(2): p. 273-286.

18. United States Department of State Bureau of Democracy, 2018 Country Reports on Human Rights Practices: Democratic Republic of the Congo. 2018.

19. United Nations Human Rights, Basic Principles for the Treatment of Prisoners. Adopted and proclaimed by General Assembly resolution 45/111 of 14 December 1990. 1990.

20. Kahleova, H., et al., Meal frequency and timing are associated with changes in body mass index in Adventist Health Study 2. The Journal of nutrition, 2017. 147(9): p. 1722-1728.

21. News24, DR Congo prisoners dying from hunger, says NGO. 2020.

22. Chop, E., et al., Food insecurity, sexual risk behavior, and adherence to antiretroviral therapy among women living with HIV: a systematic review. Health care for women international, 2017. 38(9): p. 927-944. 
23. Whittle, H.J., et al., Experiences with food insecurity and risky sex among low-income people living with HIV/AIDS in a resource-rich setting. Journal of the International AIDS Society, 2015. 18(1): p. 20293.

24. Fielding-Miller, R., et al., "There is hunger in my community": a qualitative study of food security as a cyclical force in sex work in Swaziland. BMC public health, 2014. 14(1): p. 1-10.

25. Van Hout, M.-C. and R. Mhlanga-Gunda, Prison health situation and health rights of young people incarcerated in sub-Saharan African prisons and detention centres: a scoping review of extant literature. BMC international health and human rights, 2019. 19(1): p. 1-16.

26. United States Department of State Bureau of Democracy, Sierra Leone 2017 Human Rights Report. 2017: Washington, D.C.

27. Nweze, V.N., et al., Prison health during the COVID-19 era in Africa. Public Health in Practice, 2021. 2 : p. 100083.

28. Nseluke, M.T. and S. Siziya, Prevalence and socio-demographic correlates for mental illness among inmates at lusaka central prison, Zambia. Medical Journal of Zambia, 2011. 38(2): p. 3-7.

29. Durcan, G. and J.C. Zwemstra, 11. Mental health in prison. Prisons and health, 2014: p. 87. 